\title{
Efficient Substrate Cleavage Catalyzed by Hammerhead Ribozymes Derivatized with Selenium for X-ray Crystallography
}

Gary Brandt, Nicolas Carrasco, and Zhen Huang*

Department of Chemistry, Georgia State University, Atlanta, GA 30303, \& Brooklyn College, Brooklyn, NY 11210; Huang@gsu.edu

\section{Supporting Materials}

\section{General Information}

Most solvents and reagents were purchased from Fluka, Sigma, or Aldrich (p. a.) and were used without purification unless otherwise noted. Ampliscribe T7 RNA transcription kit by Episcenter was used for transcription of the hammerhead ribozymes. Pyridine was dried and distilled over $\mathrm{KOH}$. Dioxane was dried using sodium metal and benzophenone, and was subsequently distilled. All solid reagents used were dried under high vacuum for 12 hours prior

to use. All chemical reactions were performed under Argon, except acid neutralization and $\mathrm{NaCl} / \mathrm{EtOH}$ precipitation. RNA transcription and digestion reactions were performed in air. ESI-TOF High Accuracy MS analysis was performed at the Scripps Research Institute, California. The top strand and template DNAs were synthesized by DNA synthesizer, and RNA substrate 33.1 was purchased from Dhamarcon Research, Inc. All gel electrophoresis experiments were run using $12.5 \%$ polyacrylamide gel at constant power of $5 \mathrm{~W}$ for $1.5 \mathrm{hr}$. Gels were all fixed with $10 \%$ solution of acetic acid in methanol, and dried under vacuum at $80{ }^{\circ} \mathrm{C}$ for $2 \mathrm{hr}$. Quantitation of radioactive gels was performed on BioRad phosphoimager. 


\section{Synthesis and Purification of NTPaSe}

All NTP $\alpha$ Se compounds were synthesized via a modification of TTP $\alpha \mathrm{Se}$, ATP $\alpha \mathrm{Se}$, and NTP $\alpha$ S synthesis (reference 17, 18, 21). A general procedure is described here. The starting material, 2',3'-diacetyl nucleotides $(0.100 \mathrm{mmol}$, dry), was placed in a round bottle flask $(5 \mathrm{~mL})$. Pyridine $(0.200 \mathrm{~mL})$ and dioxane $(0.200 \mathrm{~mL})$ were added into this flask to dissolve the starting material. This solution was then injected drop-wise over $5 \mathrm{~min}$ into a round bottle flask $(20 \mathrm{~mL})$ containing 2-chloro-4H-1,3,2-benzodioxaphorphorin-4-one (20.3 mg, $0.100 \mathrm{mmol}, 1 \mathrm{eq}$.$) in$ dioxane $(0.300 \mathrm{~mL})$. The reaction mixture was stirred at room temperature for 1 hour. Afterwards, a solution of pyrophosphate $(64.1 \mathrm{mg}, 0.14 \mathrm{mmol}, 1.4$ eq.) in anhydrous DMF $(0.300 \mathrm{~mL})$ and tributylamine $(0.050 \mathrm{~mL})$ was injected into the reaction mixture, and the reaction mixture was stirred for $20 \mathrm{~min}$. A solution of 3H-1,2-benzothiaselenol-3-one (43.0 mg, 0.2 $\mathrm{mmol}, 2 \mathrm{eq})$ in dioxane $(0.300 \mathrm{~mL})$ and triethylamine $(0.050 \mathrm{~mL})$ was injected into the reaction mixture. After the reaction mixture was stirred for $30 \mathrm{~min}$., ammonium hydroxide (conc., 3.0 $\mathrm{mL}$ ) was injected into the reaction mixture and reaction mixture was stirred overnight for $8 \mathrm{hr}$ at $45{ }^{\circ} \mathrm{C}$. After the $\mathrm{pH}$ of the reaction mixture was adjusted to $\mathrm{pH} 7.5-8.0$ using $80 \%$ acetic acid, the crude mixture was transported to a $50 \mathrm{~mL}$ plastic tube and centrifuged at $4000 \mathrm{rpm}$ for 15 min to remove Se metal. The supernatant was collected in two new $50 \mathrm{~mL}$ plastic tubes $(10 \mathrm{~mL}$ each), and $\mathrm{NaCl}$ solution (3.0 M, $1.1 \mathrm{~mL}$ ) and $\mathrm{EtOH}$ (thoroughly purged with $\mathrm{Ar}, 33 \mathrm{~mL}$ ) were added to each tube. After the solutions were placed in $-80{ }^{\circ} \mathrm{C}$ freezer for 10 minutes, they were centrifuged at $4000 \mathrm{rpm}$ for $15 \mathrm{~min}$. The supernatant was discarded, and the pellet was dried on high vacuum. Each solid sample was dissolved in water $(1 \mathrm{~mL})$, and combined. $\mathrm{NaCl} / \mathrm{EtOH}$ precipitation was repeated two more times, decreasing the volume each time. Finally, the crude product was dissolved in water $(0.250 \mathrm{~mL})$. 
The crude product was purified on RP-HPLC using an Agilient Zorbax C18 column (9.4 $\mathrm{mm} \times 250 \mathrm{~mm})$. The Se-modified triphosphate products were eluted $(6 \mathrm{~mL} / \mathrm{min})$ using a linear gradient from $100 \%$ buffer A $[10 \mathrm{mM}$ triethylammonium acetate (TEAA) ] to $2.5 \%$ buffer B (50\% acetonitrile in $10 \mathrm{mM}$ TEAA) in 20 minutes. The diastereomers were analyzed by RPHPLC and MS. HPLC and HR-MS analyses of UTP $\alpha$ Se diastereomers were shown in Figure 2.

\section{Activity Study of the Se-Hammerhead Ribozymes using $\mathrm{Mn}^{2+}$ as the Metal Cation}

Ribozymes were transcribed as previously discussed without the addition of any radioactive NTPs, and were desalted by centrifugation using a membrane (3000 Dalton cut-off) three times. The ribozymes were concentrated and adjusted to the same concentration on the basis of the time-course transcription experiment. A cocktail containing the Tris- $\mathrm{Cl}$ buffer $(\mathrm{pH}$ 7.6, $10 \mathrm{mM} \mathrm{MnCl}_{2}$ ) and the ${ }^{32} \mathrm{P}$-labeled RNA substrate was made, and it was split into 5 equal portions. The ribozymes transcribed with ATP $\alpha$ Se I, CTP $\alpha$ Se I, GTP $\alpha$ Se I, UTP $\alpha$ Se I, and NTPs were individually added to each portion to initiate the substrate digestion reaction incubated at 27 ${ }^{\circ} \mathrm{C}$. Aliquots $(3.5 \mu \mathrm{L}$ each) were removed from the reaction mixture at the corresponding time points and quenched individually with the loading dye $(3.5 \mu \mathrm{L})$ containing EDTA $(100 \mathrm{mM})$, followed by placing on dry ice. The digestion reactions were analyzed by PAGE (Figure S1).

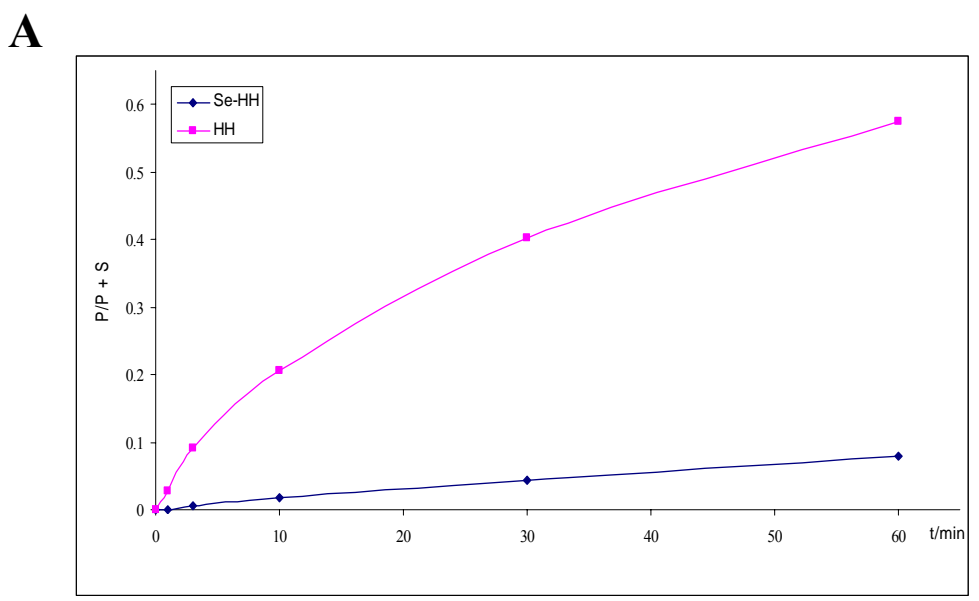




\section{B}

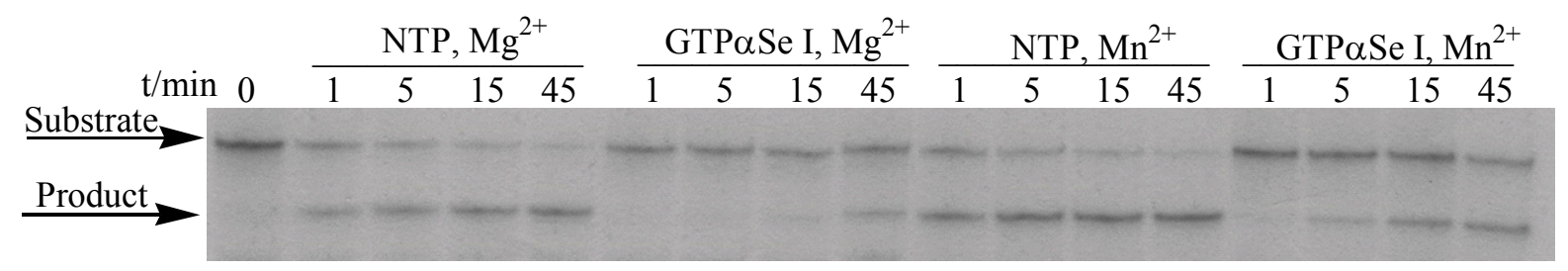

Figure S1. Catalysis of the modified and native hammerhead ribozymes: (A) The time-course $\mathrm{Mn}^{2+}$ rescue experiment of the ribozymes transcribed with ATP $\alpha$ Se I and ATP (also see Figure 4C). (B) The time-course $\mathrm{Mn}^{2+}$ rescue experiment of the ribozymes transcribed with GTP $\alpha$ Se I and GTP. 